\title{
Crescimento e produtividade de milho em função da cultura antecessora ${ }^{1}$
}

\author{
Priscila de Oliveira ${ }^{2}$, Adriano Stephan Nascente ${ }^{3}$, João Kluthcouski ${ }^{3}$, Tomás de Aquino Portes ${ }^{4}$
}

\section{ABSTRACT}

Maize growth and yield according to the previous crop

The use of cover crops in the no-tillage system can provide better conditions for the development of maize plants, with positive effects on grain yield. By using the growth analysis technique, this study aimed at characterizing the agronomic performance of maize on common bean, Brachiaria brizantha and millet straw. The experiment was carried out in a Brazilian Savannah soil, in Santo Antônio de Goiás, Goiás State, Brazil. The experimental design was randomized complete blocks, with three treatments (cover crops) and five replications. The common bean straw decomposition rate was higher than the B. Brizantha and millet ones. The highest values for the dry matter accumulation of leaves, stems, cobs and total, as well as leaf area index and maize grain yield, were observed when cultivated on common bean straw.

KEY-WORDS: Zea mays L.; Phaseolus vulgaris L.; Pennisetum glaucum L.; Brachiaria brizantha L.; no-tillage system.

\section{INTRODUÇÃO}

O milho (Zea mays L.) é o cereal mais cultivado no mundo, com produção superior a 840 milhões de toneladas, na safra 2009/2010, e produtividade média de $5.194 \mathrm{~kg} \mathrm{ha}^{-1}$, sendo o Brasil o terceiro produtor mundial, depois dos EUA e China (FAO 2012).

No Brasil, a área cultivada com essa cultura foi de 15,1 milhões de ha, na safra 2011/2012, correspondendo à produção de 72,8 milhões de toneladas, com produtividade média de $4.818 \mathrm{~kg} \mathrm{ha}^{-1}$ (Conab 2012). Entretanto, apesar da importância da cultura, sua produtividade ainda é considerada baixa, uma vez que há relatos de que o potencial produtivo da cultura é de $19.113 \mathrm{~kg} \mathrm{ha}^{-1}$ (Assis et al. 2006).

\section{RESUMO}

O uso de plantas de cobertura, no sistema plantio direto, pode proporcionar melhores condições para o desenvolvimento da cultura do milho, com reflexos positivos na produtividade de grãos. Mediante a técnica de análise de crescimento, objetivou-se, neste trabalho, caracterizar o desempenho agronômico de milho cultivado sobre palhada de feijão comum, Brachiaria brizantha e milheto. O Experimento foi conduzido em solo de Cerrado, em Santo Antônio de Goiás (GO). O delineamento experimental foi o de blocos completos casualizados, com três tratamentos (palhadas de cobertura) e cinco repetições. A velocidade de decomposição da palhada de feijão comum foi maior que a de B. brizantha e milheto. Os maiores valores de acúmulo de matéria seca das folhas, colmos, espigas e total, bem como do índice de área foliar e produtividade de grãos de milho, foram obtidos quando o cultivo ocorreu sobre palhada de feijão comum.

PALAVRAS-CHAVE: Zea mays L.; Phaseolus vulgaris L.; Pennisetum glaucum L.; Brachiaria brizantha L.; sistema plantio direto.

Entre os fatores que mais têm afetado a produtividade de milho, destacam-se o clima, manejo de nutrientes, fertilidade do solo, práticas culturais, potencial genético dos materiais e manejo de pragas e doenças (Amado et al. 2002, Fancelli \& Dourado Neto 2003).

O sistema plantio direto (SPD), manejo que preconiza o mínimo revolvimento do solo, presença de palhada na superfície do solo e rotação de culturas, tem sido uma boa alternativa de manejo, na busca por aumento de produtividade. A utilização desta prática proporciona redução no tempo despendido em operações agrícolas, aumenta os teores de matéria orgânica e a atividade biológica do solo, reduz as oscilações de temperatura do solo,

1. Trabalho recebido em jan./2013 e aceito para publicação em set./2013 (nº registro: PAT 22077).

2. Empresa Brasileira de Pesquisa Agropecuária (Embrapa Cerrados), Planaltina, GO, Brasil. E-mail: priscila.oliveira@embrapa.br.

3. Empresa Brasileira de Pesquisa Agropecuária (Embrapa Arroz e Feijão), Santo Antônio de Goiás, GO, Brasil.

E-mails: adriano.nascente@embrapa.br, joão.kluthcouski@embrapa.br.

4. Universidade Federal de Goiás (UFG), Instituto de Ciências Biológicas, Departamento de Biologia Geral, Goiânia, GO, Brasil. E-mail: portes@icb.ufg.br. 
diminui a erosão laminar, bem como o carreamento de fertilizantes e agrotóxicos para os mananciais de água, reduz a densidade populacional de plantas daninhas e possibilita maior conservação da umidade do solo, sendo, portanto, considerado um sistema de produção sustentável (Castro Filho et al. 1991, Nascente et al. 2011, Crusciol et al. 2012, Nascente \& Crusciol 2012). Por estes motivos, o SPD teve crescimento mundial significativo, sendo, atualmente, utilizado em quase 117 milhões de hectares (FAO 2012). O sistema vem, também, se expandindo no Brasil, desde a década de 1970, ultrapassando, no ano agrícola 2010/2011, 25 milhões de hectares (Febrapdp 2012).

No SPD, a decomposição da palhada de cobertura, incorporando-se, gradualmente, à matéria orgânica do solo, proporciona melhoria na estrutura e fertilidade do solo (Padovan et al. 2006), e, com a liberação de nutrientes que serão absorvidos pelas culturas sucessoras, ocorrem reflexos positivos na produtividade (Kluthcouski et al. 2000 e 2003, Oliveira et al. 2011).

Dentre as espécies utilizadas como palhada de cobertura do solo, destaca-se o milheto, apontado como uma das culturas responsáveis pela expansão do SPD na região central do Brasil, por apresentar grande quantidade de biomassa, alta resistência à seca e ciclagem de nutrientes (Kluthcouski et al. 2003, Pacheco et al. 2011).

Tem-se, ainda, constatado um crescente uso de espécies forrageiras perenes para a produção de cobertura do solo, como as braquiárias, devido ao sistema radicular profundo e vigoroso, pela excelente adaptação a solos de baixa fertilidade, fácil estabelecimento, grande produção de biomassa e alta persistência na superfície do solo (Kluthcouski et al. 2000, Santos et al. 2007, Oliveira et al. 2011, Nascente et al. 2012).

A análise de crescimento é uma técnica que detalha a alocação e partição de fotossintatos, em função da idade da planta (Falqueto et al. 2009, Concenço et al. 2011, Alvarez et al. 2012), por meio de avaliações da quantidade de fitomassa armazenada pelos seus órgãos, como folhas, caules, flores e grãos, além da sua superfície foliar (Benincasa 2003, Taiz \& Zeiger 2009).

Assim, mediante a técnica de análise de crescimento, objetivou-se, neste trabalho, caracterizar o desempenho agronômico de milho cultivado sobre palhada de feijão comum, Brachiaria brizantha $\mathrm{e}$ milheto.

\section{MATERIAL E MÉTODOS}

O experimento foi conduzido no verão do ano agrícola 2007/2008, na Fazenda Capivara, localizada no município de Santo Antônio de Goiás, GO (16² '00'S, 49¹7'00'W e 823 m de altitude). Segundo a classificação de Köppen, esta localidade apresenta clima Aw, tropical de savana, mesotérmico. A temperatura média anual varia de $20,6^{\circ} \mathrm{C}$ a $23,2^{\circ} \mathrm{C}$, com precipitação pluviométrica média de $1.485 \mathrm{~mm}$. O solo é classificado como Latassolo Vermelho distrófico de textura argilosa (Embrapa 2006a). Antes da instalação do experimento, foram coletadas amostras para análise química do solo, nas camadas $0-0,10 \mathrm{~m}$ e 0,10-0,20 m (Tabela 1).

A área experimental começou a ser cultivada sob SPD em 2005/2006, com a cultura do milho, sendo cultivada com feijão no inverno de 2006 e milho + B. brizantha consorciado no verão de $2006 / 2007$. No inverno de 2007, foram cultivados feijão comum, B. brizantha e milheto, para serem utilizados como cobertura no cultivo do milho, no verão de 2007/2008.

$\mathrm{O}$ delineamento experimental foi o de blocos completos casualizados, com três tratamentos e cinco repetições. Os tratamentos consistiram de palhadas de cobertura oriundas do cultivo de feijão (Phaseolus vulgaris L.), B. brizantha e milheto [Pennisetum glaucum (L.) R. Br.]. Cada parcela experimental apresentava área total de $45,0 \mathrm{~m}^{2}$ (10 linhas de 5,0 m, espaçadas em $0,90 \mathrm{~m}$ ), sendo metade (segunda, terceira, oitava e nona linhas) destinada à coleta de plantas e a outra metade (quarta, quinta, sexta e sétima linhas) à avaliação da produtividade e seus componentes. A primeira e última linhas, juntamente com os $0,5 \mathrm{~m}$

Tabela 1. Atributos químicos do solo (0-10 cm e 10-20 cm) (Santo Antônio de Goiás, 2007/2008).

\begin{tabular}{|c|c|c|c|c|c|c|c|c|c|c|c|c|}
\hline Profundidade & \multirow{2}{*}{$\begin{array}{c}\mathrm{pH} \\
\text { água }\end{array}$} & $\mathrm{Ca}$ & $\mathrm{Mg}$ & $\mathrm{Al}$ & $\mathrm{H}+\mathrm{Al}$ & $\mathrm{P}$ & $\mathrm{K}$ & $\mathrm{Cu}$ & $\mathrm{Zn}$ & $\mathrm{Fe}$ & $\mathrm{Mn}$ & \multirow{2}{*}{$\frac{\mathrm{MO}}{\mathrm{g} \mathrm{dm}^{-3}}$} \\
\hline $\mathrm{cm}$ & & \multicolumn{4}{|c|}{ 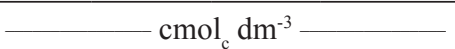 } & \multicolumn{6}{|c|}{$-\mathrm{mg} \mathrm{dm}^{-3}$} & \\
\hline $0-10$ & 6,1 & 2,6 & 0,9 & 0,0 & 5,1 & 5,8 & 218 & 3,6 & 4,2 & 33 & 51 & 23 \\
\hline $10-20$ & 5,8 & 2,3 & 0,6 & 0,0 & 5,0 & 2,9 & 104 & 3,5 & 4,2 & 32 & 47 & 19 \\
\hline
\end{tabular}


das extremidades das linhas, foram consideradas bordadura.

A dessecação das plantas, para formação de cobertura do solo, foi realizada 15 dias antes da semeadura (DAS) do milho, na dose de 6,0 $\mathrm{L} \mathrm{ha}^{-1}$ de glyphosate. A semeadura mecânica do milho híbrido BRS 1030 ocorreu no dia 24/11/2007, no espaçamento de $0,90 \mathrm{~m}$ e densidade de 6,8 sementes $\mathrm{m}^{-1}$. A adubação de semeadura foi de $300,0 \mathrm{~kg} \mathrm{ha}^{-1}$ do formulado 05-30-15. As sementes de milho foram tratadas com inseticida à base de carbofuran $(2,0 \mathrm{~L}$ do produto comercial para cada $100,0 \mathrm{~kg}$ de sementes). A emergência ocorreu seis dias após a semeadura e, aos seis dias após a emergência (DAE), foi realizada a adubação de cobertura mecanicamente, na dose de $67,5 \mathrm{~kg} \mathrm{ha}^{-1}$ de $\mathrm{N}$ (ureia). Os tratos culturais foram realizados de acordo com as recomendações para a cultura (Embrapa 2006b). Assim, o controle de plantas daninhas foi feito aos $12 \mathrm{DAE}$, com aplicação de $0,6 \mathrm{~L} \mathrm{ha}^{-1}$ de nicosulfuron $+3,0 \mathrm{~L} \mathrm{ha}^{-1}$ de atrazina. Estas aplicações foram feitas com pulverizador costal manual, com volume de calda de 200,0 $\mathrm{L} \mathrm{ha}^{-1}$.

Para avaliar a decomposição das palhadas de cobertura do solo, foram realizadas amostragens em todas as parcelas, em quatro épocas: aos 0,30, $60 \mathrm{e}$ 90 dias após a semeadura. Para tal, utilizou-se um quadrado de $25,0 \mathrm{~cm}$ de lado $\left(625,0 \mathrm{~cm}^{2}\right)$, para delimitação da área de coleta, sendo esta realizada nas entrelinhas dos cultivos. Os materiais foram secos em estufa a $60^{\circ} \mathrm{C}$, até massa constante. A massa da matéria seca obtida foi extrapolada para hectare. Aos dados de perdas de massa das palhadas, foi ajustada equação exponencial (Dalal \& Mayer 1986).

Para a análise de crescimento, as amostragens de plantas foram realizadas a cada sete dias, a partir de 20 DAE, tendo sido coletadas duas plantas por parcela, introduzidas em sacos plásticos e conduzidas ao laboratório, aonde foi feita a separação dos colmos + bainha, limbo foliar, pendão e espiga. As áreas foliares foram tomadas utilizando-se medidor eletrônico de área foliar modelo LI-3000 (LI-COR). As partes das plantas, separadas, foram submetidas à secagem em estufa a $60^{\circ} \mathrm{C}$, até massa constante, para determinação da massa da matéria seca.

Aos dados de matéria seca total foi ajustado modelo sigmoidal de três parâmetros:

$$
Y_{M S T}=\frac{a}{1+e^{-\left(\frac{c-D A E}{b}\right)}}
$$

em que: $Y_{M S T}=$ produção estimada de matéria seca; $a=$ produção de matéria seca máxima teórica $\left(\mathrm{g} \mathrm{m}^{-2}\right)$; $b=$ inclinação da curva; $c=$ tempo no qual ocorre a inflexão da taxa instantânea de crescimento da cultura (TCC); e $D A E$ = tempo decorrido de crescimento (dias após a emergência das culturas - DAE).

Por meio da derivada da equação anterior, estimou-se a taxa instantânea de crescimento da cultura $\left(\mathrm{g} \mathrm{m}^{-2}\right.$ dia $\left.^{-1}\right)$, conforme a seguinte equação:

$$
\frac{\partial Y}{\partial t}=-\left\{\frac{a\left[-\frac{1}{b} \cdot e^{-\left(\frac{c-D A E}{b}\right)}\right]}{\left[1+e^{-\left(\frac{c-D A E}{b}\right)}\right]}\right\}
$$

Para a determinação do índice de área foliar, utilizou-se o seguinte modelo exponencial quadrático:

$$
Y_{I A F}=z \cdot e^{\left(a D A E-b D A E^{2}\right)}
$$

em que $Y_{I A F}=$ índice de área foliar estimado $\left(\mathrm{m}^{2} \mathrm{~m}^{-2}\right)$; $z=$ valor inicial do IAF (primeira coleta); $a$ e $b=$ parâmetros empíricos; e $D A E=$ tempo decorrido.

Por meio da primeira derivada da equação anterior, estimou-se a taxa instantânea de crescimento do IAF $\left(\mathrm{m}^{2} \mathrm{~m}^{-2}\right.$ dia $\left.^{-1}\right)$, conforme a equação a seguir:

$$
\frac{\partial Y}{\partial t}=. z e^{\left(a t-b t^{2}\right) * a-2 b t}
$$

O milho foi colhido no dia $05 / 06 / 2008$, sendo avaliados o estande final de plantas e a produção de grãos. As espigas foram colhidas manualmente e trilhadas em batedora de cereais Nux (modelo BC 80 III).

$\mathrm{Na}$ análise dos dados experimentais de produtividade e seus componentes de produção, utilizou-se análise de variância, e as médias foram comparadas pelo teste Tukey, a $5 \%$.

\section{RESULTADOS E DISCUSSÃO}

Em relação à decomposição das palhadas de cobertura do solo, constatou-se valores semelhantes na velocidade de perda de massa dos resíduos vegetais, sendo de $0,0251 \mathrm{~kg} \mathrm{ha}^{-1} \mathrm{dia}^{-1}, 0,0226 \mathrm{~kg} \mathrm{ha}^{-1} \mathrm{dia}^{-1}$ e $0,0201 \mathrm{~kg} \mathrm{ha}^{-1} \mathrm{dia}^{-1}$, para B. brizantha, milheto e feijão comum, respectivamente. Desta forma, no período de 90 dias, ocorreu a decomposição de, aproximadamente, $50 \%$ da palhada original de $B$. brizantha, $60 \%$ de milheto e $70 \%$ de feijão (Figura 1). 
Braz et al. (2005), Pacheco et al. (2011) e Nascente \& Crusciol (2012) também relataram que o milheto apresenta rápida degradação, após a dessecação de manejo. $\mathrm{O}$ feijão comum, por possuir menor relação $\mathrm{C} / \mathrm{N}$, também possui baixa persistência de palhada no solo (Kluthcouski et al. 2003, Oliveira et al. 2011, Pacheco et al. 2011).

Constatou-se que, independentemente da palhada utilizada, aos dados de acúmulo de massa seca total da planta de milho foi ajustada a equação do tipo sigmoide (Figura 2), concordando com os relatos de Gava et al. (2010), que trabalharam com híbrido simples de milho. Assim, verificou-se que houve pequeno acúmulo de matéria seca até os 30-35 DAE, acúmulo quase que linear até os $100 \mathrm{DAE}$ e, novamente, redução do acúmulo até o final do ciclo. Estas diferentes fases de acúmulo de matéria seca, caracterizadas neste experimento, foram semelhantes àquelas reportadas por Gava et al. (2010), em que ocorre uma fase inicial de crescimento lento, seguida de uma fase de crescimento rápido, com acúmulo de $80-90 \%$ de toda a matéria seca, logo após podendo ocorrer uma fase final em que o crescimento torna-se novamente lento, acumulando cerca de $7-9 \%$ da matéria seca total.

No presente experimento, o crescimento foi contínuo até o final do ciclo da cultura. O acúmulo de matéria seca do milho teve ajuste à curva sigmoidal, com incrementos praticamente lineares dos 40 aos 80 DAE e máximo acúmulo ocorrendo entre 100 e 110 DAE, quando começa a decrescer a massa total da planta, provavelmente devido à queda de folhas senescentes (Fornasieri Filho 1992, Vasconcelos et al. 1998, Von Pinho et al. 2009).

O acúmulo de matéria seca no colmo foi superior ao das folhas (Figura 2). As espigas apre-

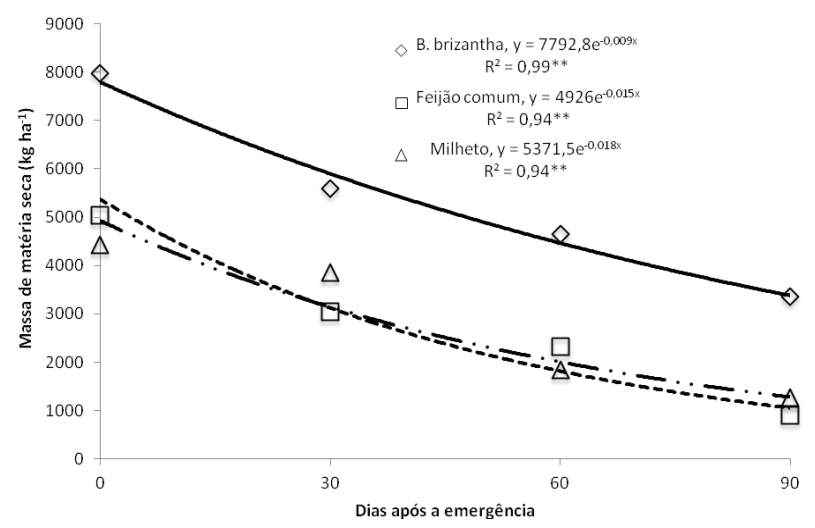

Figura 1. Decomposição de palhadas de B. brizantha, milheto e feijão comum (Santo Antônio de Goiás, 2007/2008). sentaram valores crescentes de matéria seca a partir do seu surgimento (40 DAE) até, praticamente, o final do ciclo. Assim, verificou-se maior acúmulo de matéria seca de folhas no florescimento (40 DAE), ocorrendo o de colmo mais tardiamente (60-70 DAE). Este comportamento é explicado pelo fato de que a planta prioriza a produção de folhas para a produção de fotoassimilados. Posteriormente, há a necessidade de sustentar os futuros frutos, sendo, para isto, necessário acumular matéria seca nos colmos. Vale ressaltar que, apesar de as plantas de milho ainda continuarem o processo de fotossíntese, não ocorreu incremento nos teores de matéria seca dos colmos e folhas, a partir deste período.

Por outro lado, o acúmulo de matéria seca das espigas começou a apresentar crescimento linear nesse período (60-70 DAE), provavelmente devido à translocação de fitoassimilados de folhas e colmos para as espigas. No final do ciclo, as espigas representaram, dentre as estruturas avaliadas, a maior contribuição para a formação da matéria seca total.
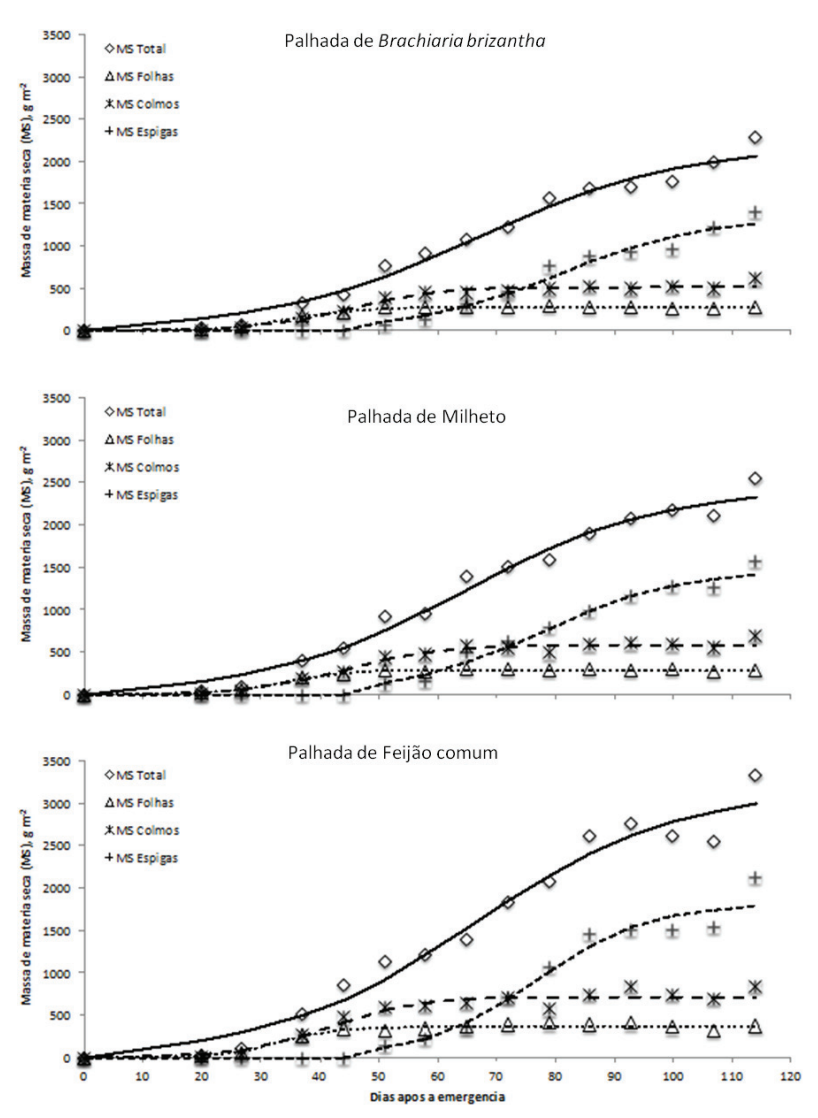

Figura 2. Acúmulo de matéria seca total, folhas, colmos e espigas de plantas de milho cultivadas sobre palhadas de B. brizantha, milheto e feijão comum (Santo Antônio de Goiás, 2007/2008). 
Com relação à palhada de cobertura, constatou-se maior acúmulo de matéria seca pelas plantas de milho cultivadas sobre palhada de feijão comum (3.000 $\left.\mathrm{g} \mathrm{m}^{-2}\right)$, seguidas de milheto $\left(2.250 \mathrm{~g} \mathrm{~m}^{-2}\right) \mathrm{e}$, por fim, de B. brizantha $\left(2.000 \mathrm{~g} \mathrm{~m}^{-2}\right.$ ) (Figura 2). Andrade (1993), em Balcarde, Argentina, observou acúmulo de matéria seca de milho de $2.250 \mathrm{~g} \mathrm{~m}^{-2}$, enquanto Braz et al. (2005) encontraram $1.749 \mathrm{~g} \mathrm{~m}^{-2}$. Estes acúmulos refletiram nas taxas de crescimento obtidas (Tabela 2), constatando-se valores de $45,9 \mathrm{~g} \mathrm{~m}^{-2} \mathrm{dia}^{-1}$, $36,4 \mathrm{~g} \mathrm{~m}^{-2} \mathrm{dia}^{-1}$ e $31,7 \mathrm{~g} \mathrm{~m}^{-2} \mathrm{dia}^{-1}$, sobre palhadas de feijão comum, milheto e $B$. brizantha, respectivamente. Valores semelhantes foram observados por Andrade (1993), na faixa de 30,0 $\mathrm{g} \mathrm{m}^{-2} \mathrm{dia}^{-1}$.

Nota-se que, independentemente do acúmulo de matéria seca, o momento de maior taxa de crescimento ocorreu entre os 65 e 67 DAE. Com este resultado, pode-se inferir que a palhada de cobertura afetou, significativamente, o crescimento da cultura, e que a palhada de feijão comum proporcionou incrementos superiores aos das demais coberturas. Avaliando-se, separadamente, as partes botânicas (folhas, colmos e espigas), observou-se que o comportamento foi semelhante, no sentido de que as plantas

Tabela 2. Taxa de crescimento instantânea (TCI) de plantas inteiras (total), folhas, colmos, espigas e índice de área foliar (IAF) de plantas de milho cultivadas sobre palhadas de Brachiaria brizantha, milheto e feijão, e momento de maior valor desta taxa (DAE) (Santo Antônio de Goiás, 2007/2008).

\begin{tabular}{|c|c|c|}
\hline Palhada & TCI total $\left(\mathrm{g} \mathrm{m}^{-2} \mathrm{dia}^{-1}\right)$ & DAE* \\
\hline Brachiaria brizantha & 31,70 & 67 \\
\hline Milheto & 36,40 & 65 \\
\hline Feijão & 45,90 & 66 \\
\hline \multicolumn{3}{|c|}{ TCI folhas $\left(\mathrm{g} \mathrm{m}^{-2} \mathrm{dia}^{-1}\right)$} \\
\hline Brachiaria brizantha & 12,41 & 35 \\
\hline Milheto & 13,23 & 34 \\
\hline Feijão & 20,00 & 33 \\
\hline \multicolumn{3}{|c|}{ TCI colmos $\left(\mathrm{g} \mathrm{m}^{-2}\right.$ dia $\left.^{-1}\right)$} \\
\hline Brachiaria brizantha & 17,28 & 45 \\
\hline Milheto & 18,17 & 44 \\
\hline Feijão & 24,30 & 41 \\
\hline \multicolumn{3}{|c|}{ TCI espigas $\left(\mathrm{g} \mathrm{m}^{-2} \mathrm{dia}^{-1}\right)$} \\
\hline Brachiaria brizantha & 27,12 & 81 \\
\hline Milheto & 31,20 & 78 \\
\hline Feijão & 55,41 & 73 \\
\hline \multicolumn{3}{|c|}{ TCI IAF $\left(\mathrm{m}^{2} \mathrm{~m}^{-2} \mathrm{dia}^{-1}\right)$} \\
\hline Brachiaria brizantha & 0,094 & 39 \\
\hline Milheto & 0,098 & 38 \\
\hline Feijão & 0,129 & 39 \\
\hline
\end{tabular}

* DAE: dias após a emergência. cultivadas em palhada de feijão comum apresentaram maiores valores de matéria seca de folhas $\left(350 \mathrm{~g} \mathrm{~m}^{-2}\right.$, $300 \mathrm{~g} \mathrm{~m}^{-2}$ e $270 \mathrm{~g} \mathrm{~m}^{-2}$, para as palhadas de feijão comum, milheto e $B$. brizantha, respectivamente), colmos $\left(700 \mathrm{~g} \mathrm{~m}^{-2}, 560 \mathrm{~g} \mathrm{~m}^{-2}\right.$ e $500 \mathrm{~g} \mathrm{~m}^{-2}$, para as palhadas de feijão comum, milheto e $B$. brizantha, respectivamente) e espiga $\left(1.480 \mathrm{~g} \mathrm{~m}^{-2}, 1.400 \mathrm{~g} \mathrm{~m}^{-2} \mathrm{e}\right.$ $1.300 \mathrm{~g} \mathrm{~m}^{-2}$, para as palhadas de feijão comum, milheto e $B$. brizantha, respectivamente) (Figura 2). Estes resultados refletiram as taxas de máximo crescimento das partes botânicas sobre estas palhadas (Tabela 2).

Em relação ao IAF, observou-se que os maiores valores (cerca de $6,0 \mathrm{~m}^{2} \mathrm{~m}^{-2}$ ) foram obtidos para o cultivo sobre palhada de feijão comum, seguido de milheto $\left(5,0 \mathrm{~m}^{2} \mathrm{~m}^{-2}\right)$ e $B$. brizantha $\left(4,5 \mathrm{~m}^{2} \mathrm{~m}^{-2}\right)$ (Figura 3). Tais valores de IAF foram obtidos por volta dos 65 DAE, para populações de 53.333 plantas ha-1 $^{-1}$, sobre as palhadas de feijão comum e $B$. brizantha, e de 50.000 plantas ha $^{-1}$, sobre palhada de milheto. Machado et al. (1980), por ocasião do florescimento do milho, encontraram valores de $5,1 \mathrm{~m}^{2} \mathrm{~m}^{-2}$ (66 mil plantas ha $\left.\mathrm{a}^{-1}\right), 3,9 \mathrm{~m}^{2} \mathrm{~m}^{-2}$ (50 mil plantas ha- $\left.{ }^{-1}\right)$ e $2,8 \mathrm{~m}^{2} \mathrm{~m}^{-2}$ (33 mil plantas ha ${ }^{-1}$ ), enquanto Braz et al. (2005) observaram valor máximo de IAF do milho igual a $3,77 \mathrm{~m}^{2} \mathrm{~m}^{-2}$, obtido aos $60 \mathrm{DAE}$.

Em relação à taxa de crescimento do IAF, ou seja, à sua intensidade de aumento, foram observados valores muito semelhantes nos cultivos sobre palhadas de $B$. brizantha e milheto (0,094-0,098 $\left.\mathrm{m}^{2} \mathrm{~m}^{-2} \mathrm{dia}^{-1}\right)$, porém superiores para a palhada de feijão $\left(0,129 \mathrm{~m}^{2} \mathrm{~m}^{-2} \mathrm{dia}^{-1}\right)$ (Tabela 2). Valor semelhante foi obtido por Braz et al. (2005):

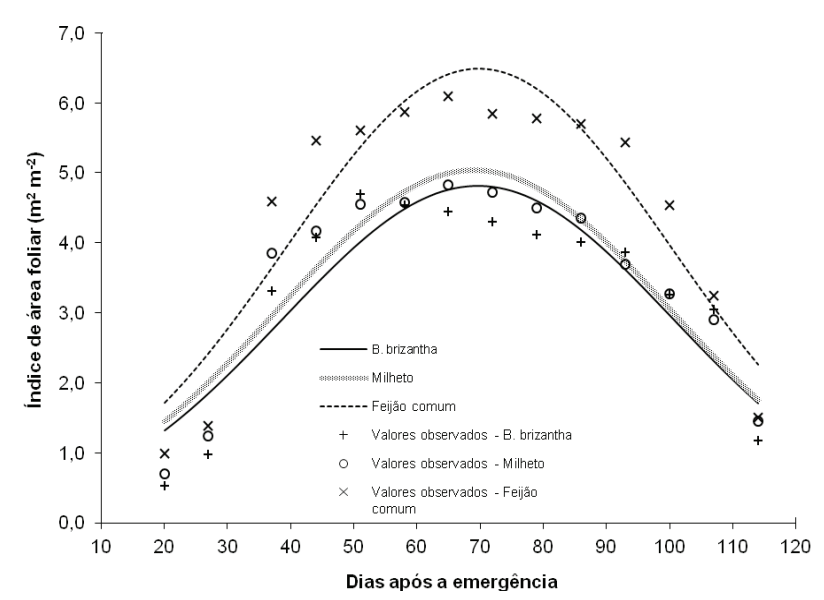

Figura 3. Índice de área foliar de milho cultivado sobre palhadas de B. brizantha, milheto e feijão comum (Santo Antônio de Goiás, 2007/2008). 
$0,09 \mathrm{~m}^{2} \mathrm{~m}^{-2} \mathrm{dia}^{-1}$, aos 34 DAE. Apesar desta diferença na taxa de crescimento do IAF, o momento de ocorrência foi praticamente igual, para os três sistemas de cultivo, ou seja, entre 38 e 39 DAE. Após este período, houve redução do IAF sobre todas as coberturas. Tal redução, no final do ciclo das culturas, deve-se à redução da área foliar útil, com a senescência da planta, morte e queda de folhas (Campos et al. 2008, Alvarez et al. 2012).

Com relação ao estande de plantas, verificou-se que não houve diferenças entre as palhadas de cobertura (Tabela 3), o que foi um indicativo de que as plantas de cobertura não afetaram o desenvolvimento inicial e estabelecimento das plantas de milho.

Avaliando-se o efeito das palhadas de cobertura na produção de grãos de milho, contatou-se que as maiores produtividades ocorreram sobre feijão comum, não se observando diferenças entre milheto e $B$. brizantha. Com base nestes resultados, pode-se inferir que a palhada de feijão comum proporcionou melhores condições para o desenvolvimento do milho, com reflexos positivos na produtividade, condições, estas, que podem estar ligadas à liberação mais rápida de nutrientes, como o nitrogênio.

Além disso, pela análise de crescimento, verificaram-se maiores valores de acúmulo de matéria seca pelas folhas, colmos e espigas, e, por conseguinte, da planta total e do IAF sobre esta palhada, o que pode explicar as maiores produtividades. Resultados similares foram encontrados por vários autores (Santos \& Costa 1997, Antoniazzi \& Deschamps 2006, Campos et al. 2008, Von Pinho et al. 2009, Gava et al. 2010).

A menor produtividade obtida sobre as gramíneas milheto e $B$. brizantha pode ser explicada pela disponibilidade de nitrogênio para a planta de milho. O milho é cultura altamente exigente em nutrientes,

Tabela 3. Estande de plantas e produtividade de grãos de milho, em função das palhadas de cobertura do solo e do local de condução do experimento (Santo Antônio de Goiás, 2007/2008).

\begin{tabular}{lcc}
\hline \multirow{2}{*}{ Palhada de cobertura } & Estande & Produtividade \\
\cline { 2 - 3 } & plantas $\mathrm{m}^{-1}$ & $\mathrm{~kg} \mathrm{ha}^{-1}$ \\
\hline Brachiaria brizantha & $4,8 \mathrm{a}^{1}$ & $6.601 \mathrm{~b}$ \\
Milheto & $4,5 \mathrm{a}$ & $6.801 \mathrm{~b}$ \\
Feijão & $4,8 \mathrm{a}$ & $8.133 \mathrm{a}$ \\
\hline DMS $^{2}$ & 1,3 & 870 \\
\hline CV $(\%)$ & 14,0 & 12,7 \\
\hline
\end{tabular}

${ }^{1}$ Médias seguidas da mesma letra minúscula, na coluna, não diferem entre si, a $5 \%$, pelo teste Tukey. ${ }^{2}$ DMS: diferença mínima significativa. principalmente o nitrogênio, que é absorvido em maior quantidade pela cultura (Araújo et al. 2004).

Plantas de cobertura de alta relação C/N (gramíneas) podem proporcionar redução na disponibilidade de nitrogênio para o milho, causando redução na produtividade. Segundo Araújo et al. (2004), a soja, como antecedente cultural, proporcionou aumento superior a 30\% na produtividade de grãos de milho, em relação à rotação com gramínea. Neste sentido, o feijão comum, mesmo não sendo caracterizado como planta fixadora de nitrogênio no solo, apresenta baixa relação $\mathrm{C} / \mathrm{N}$, causando menor imobilização deste nutriente e tornando-o mais rapidamente disponível para as plantas de milho.

Vale ressaltar que as plantas de cobertura B. brizantha e milheto são extremamente importantes para o sistema plantio direto, devido à grande produção de matéria seca, sistema radicular vigoroso, resistência à seca e ciclagem de nutrientes. Entretanto, para serem utilizadas antecedendo a cultura do milho, especial atenção deve ser destinada ao manejo da adubação nitrogenada, para evitar queda de produtividade.

\section{CONCLUSÕES}

1. A velocidade de decomposição da palha de feijão comum é maior que a de $B$. brizantha e milheto.

2. Os maiores valores de acúmulo de matéria seca nas folhas, colmo, espigas e total, bem como os maiores IAF e produtividade de grãos de milho, foram obtidos quando este foi cultivado sobre palhada de feijão comum.

\section{REFERÊNCIAS}

AMADO, T. J. C. et al. Recomendação de adubação nitrogenada para o milho no RS e SC adaptada ao uso de culturas de cobertura do solo, sob plantio direto. Revista Brasileira de Ciência do Solo, Viçosa, v. 26, n. 1, p. 241248, 2002.

ANDRADE, F. H. Crecimiento y rendimiento comparados de maiz, girasol y soja. Balcarce: INTA/EEA, 1993. (Boletín técnico, 114).

ANTONIAZZI, N.; DESCHAMPS, C. Análise de crescimento de duas cultivares de cevada após tratamentos com elicitores e fungicidas. Ciência Rural, Santa Maria, v. 36, n. 4, p. 1065-1071, 2006.

ALVAREZ, R. C. F. et al. Análise de crescimento e produtividade de cultivares de arroz de terras altas dos 
tipos tradicional, intermediário e moderno. Pesquisa Agropecuária Tropical, Goiânia, v. 42, n. 4, p. 397-406, 2012.

ARAÚJO, E. S. et al. Quantificação do N do solo derivado das raízes da soja utilizando o isótopo ${ }^{15} \mathrm{~N}$. Revista Universidade Rural, Seropédica, v. 24, n. 1, p. 7-12, 2004.

ASSIS, J. P. et al. Simulação estocástica de atributos do clima e da produtividade potencial de milho utilizando-se distribuição triangular. Pesquisa Agropecuária Brasileira, Brasília, DF, v. 41, n. 3, p. 539-543, 2006.

BENICASA, M. M. P. Análise de crescimento de plantas: noções básicas. 2. ed. Jaboticabal: Funep, 2003.

BRAZ, A. J. B. P.; KLIEMANN, H. J.; SILVEIRA, P. M. da. Produção de fitomassa de espécies de cobertura em Latossolo Vermelho distroférrico. Pesquisa Agropecuária Tropical, Goiânia, v. 35, n. 1, p. 55-64, 2005.

CAMPOS, M. F. de et al. Análise de crescimento em plantas de soja tratadas com substâncias reguladoras. Revista Biotemas, Botucatu, v. 21, n. 3, p. 53-63, 2008.

CASTRO FILHO, C. et al. Tillage methods and soil and water conservation in Southern Brasil. Soil Tillage and Research, Amsterdan, v. 20, n. 2-4, p. 271-293, 1991.

COMPANHIA NACIONAL DE ABASTECIMENTO (Conab). Levantamento da produção de grãos: safra 2010/11. 2012. Disponível em: <www.conab.gov.br>. Acesso em: 25 fev. 2012.

CONCENÇO, G. I. et al. Photosynthetic characteristics of hybrid and conventional rice plants as a function of plant competition. Planta Daninha, Viçosa, v. 29, n. 4, p. 803-809, 2011.

CRUSCIOL, C. A. C. et al. An innovative crop-forage intercrop system: early cycle soybean cultivars and palisadegrass. Agronomy Journal, Madison, v. 104, n. 4, p. 1085-1095, 2012.

DALAL, R. C.; MAYER, R. J. Long-term trends in fertility of soils under continuous cultivation and cereal cropping in Southern Queensland: II. Total organic carbon and its rate of loss from the soil profile. Australian Journal of Soil Research, Victoria, v. 24, n. 2, p. 281-292, 1986.

EMPRESA BRASILEIRA DE PESQUISA AGROPECUÁRIA (Embrapa). Centro Nacional de Pesquisa de Solos. Sistema brasileiro de classificação de solos. 2. ed. Rio de Janeiro: Embrapa Solos, 2006a.

EMPRESA BRASILEIRA DE PESQUISA AGROPECUÁRIA (Embrapa). Centro Nacional de Pesquisa de Milho e Sorgo. Cultivo do milho. 2. ed. Sete Lagoas: Embrapa Milho e Sorgo, 2006b. (Sistema de produção, 1).
FALQUETO, A. R. et al. Partição de assimilados em cultivares de arroz diferindo no potencial de produtividade de grãos. Bragantia, Campinas, v. 68, n. 3, p. 453-461, 2009.

FANCELLI, A. L.; DOURADO NETO, D. Milho: estratégias de manejo para alta produtividade. Piracicaba: ESALQ/USP/LPV, 2003.

FEDERAÇÃO BRASILEIRA DE PLANTIO DIRETO NA PALHA (Febrapdp). Evolução do plantio direto no Brasil. 2012. Disponível em: <http://www.febrapdp.org. br/arquivos/EvolucaoAreaPDBr72A06.pdf $>$. Acesso em: 31 mar. 2012.

FOOD AND AGRICULTURE ORGANIZATION (FAO). Production: crops. 2012. Disponível em: <www.faostat. fao.org>. Acesso em: 29 mar. 2012.

FORNASIERI FILHO, D. A cultura do milho. Jaboticabal: Funep, 1992.

GAVA, G. J. C. et al. Produção de fitomassa e acúmulo de nitrogênio em milho cultivado com diferentes doses de ${ }^{15} \mathrm{~N}$-ureia. Semina: Ciências Agrárias, Londrina, v. 31, n. 4, p. 851-862, 2010.

KLUTHCOUSKI, J. et al. (Eds.). Integração lavourapecuária. Santo Antônio de Goiás: Embrapa Arroz e Feijão, 2003.

KLUTHCOUSKI, J. et al. Sistema Santa Fé - tecnologia Embrapa: integração lavoura-pecuária pelo consórcio de culturas anuais com forrageiras, em áreas de lavoura, nos sistemas direto e convencional. Santo Antônio de Goiás: Embrapa Arroz e Feijão, 2000. (Circular técnica, 38).

MACHADO, E. C. et al. Análise de crescimento de quatro variedades de milho em três diferentes populações: I. Análise quantitativa do crescimento através de funções ajustadas. In: REUNIÃO BRASILEIRA DE MILHO E SORGO, 13., 1980, Londrina. Resumos... Londrina: Iapar, 1980. p. 67.

NASCENTE, A. S.; CRUSCIOL, C. A. C. Cover crops and herbicide timing management on soybean yield under notillage system. Pesquisa Agropecuária Brasileira, Brasília, DF, v. 47, n. 2, p. 187-192, 2012.

NASCENTE, A. S. et al. Brachiaria ruziziensis and herbicide on yield of upland rice. Planta Daninha, Viçosa, v. 30, n. 4, p. 729-735, 2012.

NASCENTE, A. S. et al. Desenvolvimento e produtividade de cultivares de arroz de terras altas em função do manejo do solo. Pesquisa Agropecuária Tropical, Goiânia, v. 41, n. 2, p. 186-192, 2011.

OLIVEIRA, P. de et al. Consórcio de milho com braquiária e guandu-anão em sistema de dessecação parcial. Pesquisa Agropecuária Brasileira, Brasília, DF, v. 46, n. 10, p. 11841192, 2011. 
PACHECO, L. P. et al. Produção de fitomassa e acúmulo e liberação de nutrientes por plantas de cobertura na safrinha. Pesquisa Agropecuária Brasileira, Brasília, DF, v. 46, n. 1, p. 17-25, 2011.

PADOVAN, M. P. et al. Decomposition and nutrient release from soybean cut at different growth stages. Pesquisa Agropecuária Brasileira, Brasília, DF, v. 41, n. 4, p. 667-672, 2006.

SANTOS, A. B. dos; COSTA, J. D. Crescimento de arroz de sequeiro em diferentes populações e irrigação suplementar. Pesquisa Agropecuária Brasileira, Brasília, DF, v. 32, n. 10, p. 591-599, 1997.

SANTOS, R. S. M. et al. Componentes da parte aérea e raízes de pastagens de Brachiaria spp. em diferentes idades após a reforma, como indicadores de produtividade em ambiente de Cerrado. Pesquisa Agropecuária Tropical, Goiânia, v. 37, n. 2, p. 119-124, 2007.
TAIZ, L.; ZEIGER, E. Fisiologia vegetal. 4. ed. Porto Alegre: Artmed, 2009.

VASCONCELLOS, C. A. et al. Acúmulo de matéria seca e de nutrientes em milho cultivado no período invernoprimavera. Pesquisa Agropecuária Brasileira, Brasília, DF, v. 33, n. 11, p. 1835-1845, 1998.

VON PINHO, R. G. et al. Avaliação agronômica do cultivo de milho em diferentes níveis de investimento. Ciência e Agrotecnologia, Lavras, v. 33, n. 1, p. 39-46, 2009. 